\title{
Papel Social e Emancipação: \\ Discutindo as Bases da Profissão Docente
}

\author{
Social Role and Emancipation: \\ Discussing the Foundations of the Teacher Profession
}

Marcos Gustavo RICHTER *
Joseane AMARAL **

Resumo: A constituição do papel social do professor de línguas ainda é pouco discutida no meio acadêmico. $O$ presente artigo tem por objetivo acender este debate, estabelecendo um contraponto com a única licenciatura que possui regulamentação própria: a Educação Física. Com os aportes metodológicos da Linguística de Corpus, analisamos textos de periódicos, assinalando as diferenças entre estas duas profissões ligadas à esfera educacional, embora distintas em termos legais. Os resultados apontam para a emergência de um discurso endógeno no caso das profissões de maioridade jurídica, em contraposição à exogenia discursiva que marca as intervenções nas (semi)profissões.

Palavras-chave: Papel social; Atribuição; Professor.

Abstract: The constitution of the social role of Language teachers is little discussed in academic circles. This article aims to illuminate this discussion, providing a counterpoint to the unique Bachelors' degree that has its own regulations: Physical Education. With the methodological contributions of Corpus Linguistics, we reviewed journal texts, marking

* Professor Titular Pós-Doutor da Universidade Federal de Santa Maria Departamento de Letras Vernáculas. Doutor em Comunicação e Semiótica pela Pontifícia Universidade Católica de São Paulo e Pós-Doutor em Linguística de Corpus pela Pontifícia Universidade Católica de São Paulo. Contato: richtermg@gmail.com

** Mestranda no Programa de Pós-Graduação em Letras, área de Estudos Linguísticos, da Universidade Federal de Santa Maria. Bolsista Capes. Contato: josi.ibiruba@gmail.com 
the differences between these two educational professions, different in legal terms. The results point to the emergence of an indigenous discourse in emancipated professions, in contrast to an exogenous one that marks the interventions in (semi) professions.

Key-words: Teacher; Social role; Emancipation.

\section{Introdução}

A discussão sobre a necessidade de conferir emancipação profissional ao docente da área de Letras pode ser considerada relativamente recente. No entanto, face às mudanças na educação, ela se faz mais do que necessária no contexto da complexidade e da contingência da sociedade moderna.

Entretanto, para que possamos colocar em pauta a maioridade jurídica deste profissional, queremos antes discutir: em que cenário e nível normativo atua o professor de Letras? Que papel social ele desempenha? Há diretrizes delimitando seu papel? E ainda: quais são elas, e quem as delimita?

Para alimentar nossas discussões, apontaremos o exemplo da única licenciatura dotada de maioridade profissional: a Educação Física. Em linhas gerais, o presente artigo pretende acender o debate entre as profissões emancipadas versus profissões reconhecidas, por meio da análise e comparação de textos de revistas pertencentes às duas áreas acima citadas. Através dos aportes da Linguística de Corpus, a análise pretende apontar as diferenças na constituição dos discursos endógenos, em profissões emancipadas, ao contrário da constituição exógena das profissões apenas reconhecidas.

\section{Professor: que papel social é esse?}

Definir o trabalho do professor não é tarefa fácil. Há várias pesquisas ${ }^{1}$, inclusive na área de ergonomia, que buscam definições concretas para o agir docente, mas elas esbarram na complexidade

${ }^{1}$ Entre as leituras que inspiraram nossas reflexões estão Machado (2007) e Bronckart (2006), cujas referências completas encontram-se no final do artigo. 
das atribuições deste profissional, uma vez que não se trata apenas da produção de um serviço, mas de uma atividade intelectual sem garantias, pois, sendo voltada a outro, não há como certificar-se de que seja aceito e/ou assimilado o que o professor pretende ensinar.

Para discutir as entrelinhas do trabalho docente, um dos pontos de partida é analisar como se dá a constituição da categoria de papel social. Isto implica reconhecer que, antes de desempenhar os papéis, o sujeito deve conhecê-los. Avaliar o papel social sobre o qual se fundem as atribuições docentes é uma das premissas para defender as diretrizes da profissão.

Segundo Dahrendorf (1969), Shakespeare pode ter antecipado a particularidade e a possibilidade da categoria papel social, como se pode depreender através da leitura do trecho da peça shakespeariana "As you like it".

All the world's a stage,

And all the men and women merely players:

They have their exits and their entrances;

And one man in his time plays many parts,

His acts being seven ages. At first the infant,

Mewling and puking in the nurse's arms.

And then the whining school-boy, with his satchel

And shining morning face, creeping like snail

Unwillingly to school. And then the lover,

Sighing like furnace, with a woeful ballad

Made to his mistress' eyebrow. Then a soldier,

Full of strange oaths and bearded like the pard,

Jealous in honour, sudden and quick in quarrel,

Seeking the bubble reputation

Even in the cannon's mouth. And then the justice,

In fair round belly with good capon lined,

With eyes severe and beard of formal cut,

Full of wise saws and modern instances;

And so he plays his part. The sixth age shifts

2 A tradução do texto encontra-se no anexo 1. 
Into the lean and slipper'd pantaloon,

With spectacles on nose and pouch on side,

His youthful hose, well saved, a world too wide

For his shrunk shank; and his big manly voice,

Turning again toward childish treble, pipes

And whistles in bis sound. Last scene of all,

That ends this strange eventful history,

Is second childishness and mere oblivion,

Sans teeth, sans eyes, sans taste, sans everything.

O fragmento aponta diferentes momentos da vida do homem, como a infância, a adolescência e a fase adulta, que representariam, consequentemente, diferentes papéis do indivíduo. As sete idades do homem, simulando vários estágios da vida, seriam, na peça teatral publicada em 1623, uma antecipação da categoria de papel social.

De acordo com o trecho acima, o mundo é um palco no qual o indivíduo está presente não apenas para uma apresentação; nessas idas e voltas ele surge e desaparece, sempre com máscaras diferentes. Nesse contexto, Dahrendorf (1969, p. 43) defende que os termos "papel, pessoa, caráter e máscara são palavras que, apesar de provenientes de estágios diversos do desenvolvimento linguístico, têm uma área de significado comum: o teatro". A metáfora de Shakespeare pode ser transposta para o estudo desta categoria sociológica tão importante e que preexiste ao sujeito: o papel social.

Assim, Dahrendorf (1969, p. 54) esclarece que "papéis sociais são feixes de expectativas, que se ligam, em uma determinada sociedade, ao comportamento dos portadores de posições". Ainda conforme o pensador social (DAHRENDORF, 1969, p. 52), o campo de posições no qual o indivíduo se vê colocado, ocupando uma determinada posição, pode implicar numa pluralidade de relações diferenciáveis.

A posição "professor" consiste nos segmentos posicionais "professor-aluno", "professor-pais de alunos", "professor-colegas", "professor-superiores", onde cada um dos segmentos seleciona uma direção relacional no campo de posições do professor. Tais posições são demarcadas pelo papel social a que pertencem os indivíduos, bem como pelas expectativas que os circundam. 
A noção de papel social como agregado de expectativas pode ser relacionada ao pensamento luhmanniano (1983) sobre esta temática. Na perspectiva do autor, vivemos em um mundo cercado de inúmeras possibilidades, por isso precisamos das estruturas de expectativas para selecionarmos nossas ações. Nesse quadro, Luhmann (1983) defende duas possibilidades: as expectativas cognitivas, marcadas pela adaptação e assimilação de desapontamentos; e as expectativas normativas, que permanecem como a não adaptação, sendo as possíveis discrepâncias atribuídas ao ator social. Em outros termos, as expectativas cognitivas desapontadas devem ser abandonadas; as normativas, ao contrário, se mantêm. Podemos afirmar que a expectativa cognitiva está relacionada a constantes adaptações, ao passo que a normativa mantém relação com os papéis sociais assumidos pelo sujeito. Assim, ao nível normativo, expectativas que dizem respeito a capacidades de trabalho de uma secretária, por exemplo, estão intimamente ligadas ao seu papel social, ou seja, à postura e conduta que deve ser assumida pelo sujeito em determinado contexto de atuação.

De acordo com Dahrendorf (1969, p. 55), as

expectativas aliadas ao ator do papel social professor podem ser divididas em expectativas ligadas à relação professor-alunos, professor-pais e assim por diante [...] cada papel individual é um complexo ou uma porção de expectativas de comportamento.

Ainda na perspectiva do mesmo autor:

A cada posição que uma pessoa ocupa, correspondem determinadas formas de comportamento que se esperam do portador dessa posição; a tudo que ele é, correspondem coisas que ele faz ou tem; a cada posição social corresponde um papel social. Ocupando posições sociais, o indivíduo torna-se uma pessoa do drama escrito pela sociedade em que vive [...] enquanto as posições apenas indicam locais em campos de referência, o papel revela a natureza das relações entre os portadores de posições e os de outras posições do mesmo campo. Papéis sociais significam reivindicações da sociedade aos portadores de posições [...] (DAHRENDORF, 1969, p. 54). 
Nessas diretivas, refletindo sobre o papel social do professor de Letras, podemos afirmar que a atuação deste profissional é, em grande parte, marcada por expectativas cognitivas, uma vez que precisa estar constantemente readequando-se às reivindicações de sistemas de ensino. Destacamos o professor de Letras, uma vez que se trata do objeto de nossa pesquisa. Além disso, sabe-se que há profissionais que atuam também como educadores e não partilham da mesma situação, como o nutricionista e o educador físico.

A situação fica exemplificada no relacionamento com alguns dos segmentos elencados acima. Muitas vezes, o profissional de educação age buscando satisfazer às exigências de outrem, sem que se pense, primordialmente, nas finalidades do ensino. Sobre esse aspecto, a Teoria Holística da Atividade (THA) de Richter (2006) faz menção a esta ocorrência pela denominação "desvio aos meios", fenômeno segundo o qual as finalidades da atividade são deixadas de lado para que se possa atender aos meios, ou seja, tornar a atividade "agradável" ao aluno.

É seguro afirmar que boa parte disso deve-se ao fato de a licenciatura em Letras encontrar-se no patamar de uma (semi)profissão, como salienta Richter (s.d.). Nesse contexto, nos afiliamos à interpelação de Dahrendorf (1969): como poderá ser garantida a obrigatoriedade das expectativas dos papéis sociais? Nossa resposta, que imbui de esperanças o futuro da docência, diz respeito à garantia da maioridade jurídica, etapa que estabelece grandes diferenças entre profissões emancipadas e regulamentadas.

\section{Emancipação profissional e estabilização de expectativas}

Parece contraditório e paradoxal admitir que, ainda no século XXI, o profissional que atua como formador esteja desapropriado de um lugar social, atuando em condições que comprovam a sua minoridade jurídica. Nesse sentido, pensar na emancipação é buscar o reconhecimento do papel do professor na sociedade, condição sine qua non para garantir uma prática voltada ao bem social.

Com base em Ticks (2005), Richter (2008, p. 11) aponta que tanto acadêmicos quanto profissionais demonstram grandes dificuldades em construir um perfil identitário de professor, uma vez que os 
construtos discursivos que o interpelam são difusos e contraditórios, além de se constituírem a partir de setores sociais externos - fenômeno denominado exogenia discursiva. Nesse sentido, esse movimento em que elementos migram de uma esfera social a outra é responsável pelas modificações dos papéis sociais, cujas alterações se processam ao longo da história.

Sobre isso, também são pertinentes as palavras de Dahrendorf (1969, p. 62), para quem

o grau de institucionalização dos papéis sociais, isto é, o grau até onde os preceitos são sancionados legalmente, nos fornece uma unidade de medida para o significado dos papéis tanto para o indivíduo como para a sociedade.

Concordamos com o autor e afirmamos que é nítida a diferença na atuação de um médico, cuja profissão possui status e prestígio na sociedade. Nessa esfera profissional não são permitidas interferências de pseudoprofissionais, e as tentativas de exercício ilegal da medicina são devidamente punidas. Para tanto, existem os Conselhos Federal e Regionais atuando na garantia de fiscalização. A realidade do professor, ao contrário, demonstra a ausência de institucionalização de seu papel. Seu trabalho é constantemente desvalorizado, sendo muitas vezes delegado a pessoas sem a devida formação, deixando transparecer que as diretrizes de sua profissão são marcadas por expectativas cognitivas, isto é, permanece a constante adaptação do profissional à realidade que se apresenta, e não a busca pela manutenção das normas, o que deixaria clara a presença de expectativas normativas. O trabalho de Richter (2010, p. 2) explica com nitidez esta relação:

Sistemas sociais do tipo pré-normativo - segundo a THA, alopoiéticos e constituídos por exogenia discursiva, caso típico de profissões não regulamentadas, como a licenciatura em Letras - caracterizam-se por experiências regidas cognitivamente, o que não significa ausência de convenções e sanções, e sim, 'que os componentes cognitivos e normativos das expectativas formam uma unidade coesa' [...] Ou seja, nos sistemas baseados em expectativas cognitivas, ordens e sanções são sensíveis a 
contexto, não havendo consenso dentro da classe profissional a respeito dessas questões.

A ausência de consenso apontada acima torna, de certa forma, instáveis as relações entre os pares e até mesmo entre profissional e cliente nesta profissão. Por isso, muitas vezes, é possível perceber a interferência de outras áreas nos rumos da docência, como se fosse correto aceitar passivamente que outros domínios determinassem como o profissional das Letras deve proceder. Nesse sentido, é possível analisar que

[...] essa capacidade de os dominados incorporarem o discurso dos dominadores (Elias - Os Estabelecidos e os Outsiders) relata um estudo realizado em uma pequena comunidade, onde a diferença entre seus moradores consistia apenas no tempo de residência, constatando uma recorrência nas relações que se estabelecem entre os grupos, a partir da inferência de que praticamente em todas as sociedades os grupos estabelecidos há mais tempo, com história de vida em comum, estigmatizam outros grupos como sendo de status inferior e de menor valor. Discurso desse nível, quando internalizado pelos outsiders, revela que a herança social exercerá influência importante no modo de vida do grupo classificado como inferior. (RICHTER; GARCIA, 2006, p. 3)

A metáfora dos outsiders nos parece pertinente, pois demonstra as relações de poder entre dois grupos, que podem representar as relações entre profissões emancipadas, estabelecidas, cujo status social é implícito à sua esfera profissional, e profissões de minoridade jurídica, outsiders, que sofrem a determinação do discurso exterior.

Com Elias (2000) também reforçamos analogamente a discussão sobre o senso de pertença grupal do professor. A esfera dominante possui a identidade social de um grupo, marcada por um substantivo abstrato que os define como um coletivo: são os establishment. Por outro lado, os outsiders existem sempre no plural, não constituindo propriamente um grupo social. Essa ausência de pertença grupal é característica das profissões não emancipadas, nas quais o senso de grupo, quando existe, é muito diferente das profissões regulamentadas. 
No que tange à regulamentação, o exemplo do discurso da classe dos médicos é apenas um dentre muitos outros: nutricionistas, psicólogos, economistas, biólogos, num total de 62 profissões regulamentadas no Ministério do Trabalho e Emprego, integrantes da lista da CBO - Classificação Brasileira de Ocupações. ${ }^{3}$ No inventário da $\mathrm{CBO}$, onde é possível visualizar as regulamentadas profissões de mototaxista e motoboy, garimpeiro, peão de rodeio e repentista, o professor não está incluído. Nesse sentido, nos perguntamos: em que medida a emancipação do professor de Letras pode trazer modificações ao sistema? Sobre esse assunto, explanamos a seguir, a partir do estatuto da única licenciatura emancipada: a Educação Física.

\section{Profissões Emancipadas x Profissões Reconhecidas: o exemplo da Educação Física}

O reconhecimento profissional é considerado um dos determinantes na vida do homem. Assegurar esse direito é conferir legitimidade às ações do sujeito, nas suas relações enquanto grupo social a que pertence. Nesse sentido, convém mencionar algumas proposições de Steinhilber (1996), autor de Profissional de Educação Física... existe?, das quais nos servimos para alimentar o debate sobre a emancipação nas Letras.

Inicialmente, é preciso ressaltar que a Educação Física é profissão regulamentada, de acordo com a Lei Federal n. 9.696, de 1 de setembro de $1998^{4}$, que traz a pauta e as inquietações das discussões que envolviam a tentativa de emancipação da Educação Física. Muitas daquelas proposições são absolutamente plausíveis no caso do profissional de Letras; por isso, passamos a destacar os fatores mais importantes.

Segundo Steinhilber (1996), era iminente a busca pela regulamentação, uma vez que permitir a "qualquer um" a condução de práticas de atividades físicas, desportivas e afins, poderia desmotivar futuros alunos a frequentarem os cursos de formação, desencorajando a busca por essa profissão e resultando em prejuízos à sociedade. $\mathrm{O}$

${ }^{3}$ Disponível em: <http://www.mtecbo.gov.br/cbosite/pages/ regulamentacao.jsf $>$.

${ }^{4}$ Disponível em: <http://www.planalto.gov.br/ccivil_03/Leis/L9696.htm>. 
mesmo autor esclarece que, já em 1946, ex-dirigentes de associações de professores de Educação Física clamavam pela criação de sua Ordem ou Conselho, o que não se concretizou na época.

Com relação aos passos fundamentais para estabelecer as diretrizes do processo emancipatório, nos unimos aos preceitos expostos por Steinhilber (1996, p. 77), extraídos do documento final do $10^{\circ}$ Congresso Latino-Americano de Educação Física, Desporto e Recreação e $10^{\circ}$ Encontro Nacional de Professores de Educação Física, ocorrido em 1984:

No sentido de assegurar ao Professor de Educação Física o campo que é seu por direito, sejam tomadas as seguintes providências:

a) delimitar o campo de trabalho do Professor de Educação Física;

b) reconhecer a profissão;

c) elaborar o código de ética;

d) criar os Conselhos Federal e Regional.

Essas resoluções, que antecederam a maioridade profissional da Educação Física, também cabem ao profissional de Letras. É preciso estabelecer as bases da profissão, delimitando-a em termos de área de atuação, limites de ação, reconhecimento, além de estabelecer as diretrizes dos respectivos Conselhos.

Nesse sentido, uma justificativa para a criação destes órgãos de fiscalização é a defesa da sociedade. Para o mesmo autor (STEINHILBER, 1996, p. 82), "garantido o exercício profissional, a sociedade estará dotada de mecanismos de defesa contra a prática profissional leiga e irresponsável”. Ao abordar esta questão, é importante assinalar a diferença entre profissões regulamentadas e profissões reconhecidas:

Profissões regulamentadas são aquelas que possuem seus respectivos Conselhos Profissionais, reguladores e fiscalizadores do exercício profissional. Profissões reconhecidas são aquelas que têm amparo legal, possuem escolas de formação autorizadas por autoridades competentes, porém, cujo exercício profissional 
não é regulado pelos respectivos profissionais. (STEINHILBER, 1996, p. 78).

Nesse ponto da discussão, o autor esclarece que a profissão genérica de professor é reconhecida, mas não regulamentada. Não são os próprios membros que dirigem os rumos de sua profissão, tarefa que cabe ao governo, por meio de legislação específica. No entanto, podemos afirmar que não há legislação que delimite o trabalho do professor. Apenas algumas diretrizes para o ensino são fornecidas pela Lei de Diretrizes e Bases ${ }^{5}$ e pelos Parâmetros Curriculares Nacionais - PCNs, editados em $1998^{6}$.

Cabe salientar que nossa investigação se restringe ao profissional das Letras, embora julguemos necessário mencionar tais dados a respeito da ausência de regulamentação na docência. Outro fator que merece ser esclarecido é a que a Educação Física é profissão regulamentada, e não o professor de Educação Física - é preciso perceber as diferenças desta realidade. No Estatuto do CONFEF, capítulo II - Do campo e da Atividade Profissional, o artigo $8^{\circ}$ relata as atribuições deste prestador de serviços:

Compete exclusivamente ao Profissional de Educação Física, coordenar, planejar, programar, prescrever, supervisionar, dinamizar, dirigir, organizar, orientar, ensinar, conduzir, treinar, administrar, implantar, implementar, ministrar, analisar, avaliar e executar trabalhos, programas, planos e projetos, bem como, prestar serviços de auditoria, consultoria e assessoria, realizar treinamentos especializados, participar de equipes

${ }^{5}$ Disponível em: < http://www.planalto.gov.br/ccivil_03/Leis/L9394.htm>.

${ }^{6}$ Parâmetros Curriculares Nacionais $1^{a}$ a $4^{a}$ Séries. Disponíveis em: <http:// portal.mec.gov.br/index.php?option $=$ com_content\&view $=$ article $\&$ id $=12640:$ parametros-curriculares-nacionais $10-a-4 o-$ series\&catid $=195$ :seb-educacao-basica $>$.

Parâmetros Curriculares Nacionais $5^{a}$ a $8^{a}$ Séries. Disponíveis em: <http:// portal.mec.gov.br/index.php?option $=$ com_content\&view $=$ article \&id=12657:parametros-curriculares-nacionais-5o-a-8oseries\&catid=195:seb-educacao-basica $>$. 
multidisciplinares e interdisciplinares e elaborar informes técnicos, científicos e pedagógicos, todos nas áreas de atividades físicas, desportivas e similares. ${ }^{7}$

Como demonstrado acima, não é utilizada a denominação professor, e sim Profissional de Educação Física. Ainda conforme Steinhilber (1996, p. 129), a própria LDB reforça a "importância das profissões regulamentadas quando, no capítulo referente à Educação Superior, estabelece "Art. 50 - É livre o exercício das profissões, exigida a qualificação especial, na forma da Lei, para as profissões regulamentadas."

A partir dessas colocações, levantamos a questão: que benefícios poderão ser alcançados no processo de regulamentação? Iniciamos respondendo que é preciso travar esta batalha para delimitar o que, metaforicamente, hoje representa um território de ninguém. Da mesma forma, nas palavras de Richter e Garcia (2006), para garantir visibilidade a este profissional. Ainda convém mencionar que

Há um choque de legitimidade quando a sociedade consome um produto que é fruto do trabalho de alguém que não tem legitimidade para executá-lo [...] Embora tenha competência, falta-lhe legitimidade [...] ainda que ele tenha passado por todas as provas de um curso superior, seu trabalho está à margem do mundo jurídico [...] Não deixa de ser uma espécie de piada metafísica o fato (ou não fato) do Profissional de Educação Física atuar, ser eficaz, mas não existir. (VARGAS, 1996, p. 90).

Desenvolvendo este tópico, concordamos com a ideia de que a aparência opaca de um profissional só pode resultar em desprestígio na esfera social. Assim, a resposta à necessidade de emancipação também vem com Vargas (1996): por se tratar de um direito de tornar jurídico aquilo que de fato, a sociedade consome, aceita, acredita, respalda e vive.

${ }^{7}$ Disponível em: <http://www.confef.org.br/extra/conteudo/ default.asp?id $=471>$. 


\section{Corpus Letras x Educação Física: análise e interpretação}

Acumulam-se publicações vulgarizadoras sobre a prática do professor, percebendo-se a interferência do subsistema mídia nas delimitações da profissão docente. Entrevistas com profissionais das mais diversas áreas apontam sem qualquer pudor modelos de conduta a este profissional cujo papel social é marcado pela exogenia discursiva. Curiosamente, é absolutamente incomum encontrar entrevistas com docentes indicando como deve agir um profissional externo à sua área de atuação.

Pensando em explorar esta realidade, nossa análise versa sobre uma das pilastras da Teoria Holística da Atividade (THA) de Richter (2008): os fatores de atribuição, pensados em sua relação com a atividade docente. Segundo Richter (s.d.), a atribuição compreende a modelagem do papel social, tratando dos fatores institucionais envolvidos no ato linguodidático, como os espaços onde a atividade docente é desempenhada, como são previstas as tarefas, bem como quem organiza as diretrizes e bases desta ação.

Por meio de uma análise comparativa entre duas profissões Educação Física (emancipada juridicamente) e Letras, pretendemos explicitar as diferenças entre as duas profissões. Através da apreciação de corpora distintos, analisados com recursos do programa WordSmith Tools, aspiramos mapear a atribuição e, em termos luhmannianos, as expectativas que subjazem ao papel social do professor.

Apresentamos, a seguir, uma pré-análise de nosso corpus, que reúne publicações relacionadas às duas áreas supracitadas: um relativo a exposições da Revista Educação Física, ligada ao CONFEF Conselho Federal de Educação Física; e outro contendo textos da Revista Língua Portuguesa. Ambos possuem relativamente o mesmo número de palavras, cerca de 37 mil cada. Após a seleção dos textos, feita por meio da palavra-chave "professor", passamos à limpeza, compilação e organização do corpus. Em seguida, iniciamos os procedimentos de análise através do programa WordSmith Tools.

No primeiro quadro apresentamos a lista de frequência das palavras - Wordlist - nos dois corpora selecionados. Nos quadros seguintes, expomos as telas de concordâncias dos itens motivação e profissional, em análise de caráter principiante, apenas para demonstrar 
a posição dos termos e comprovar a direção de nossas pesquisas. Nosso estudo pretende evidenciar as diferenças entre as duas profissões, no enquadramento da categoria atribuição, subcategoria Papel Social.

Quadro 1 - Comparação do corpus das revistas Língua Portuguesa e Educação Física

\begin{tabular}{||l|l||}
\hline Revista Língua Portuguesa & Revista Educação Física \\
\hline Professor: 46 & Professores: 53 \\
\hline Professora: 8 & Professor: 28 \\
\hline Professores: 8 & Docente: 5 \\
\hline Docente: 9 & Docentes: 5 \\
\hline Profissional: 6 & Profissional: 184 \\
\hline Profissionais: 4 & Profissionais: 189 \\
\hline Profissão: não consta & Profissão: 64 \\
\hline Motivação: 17 & Motivação: 2 \\
\hline
\end{tabular}



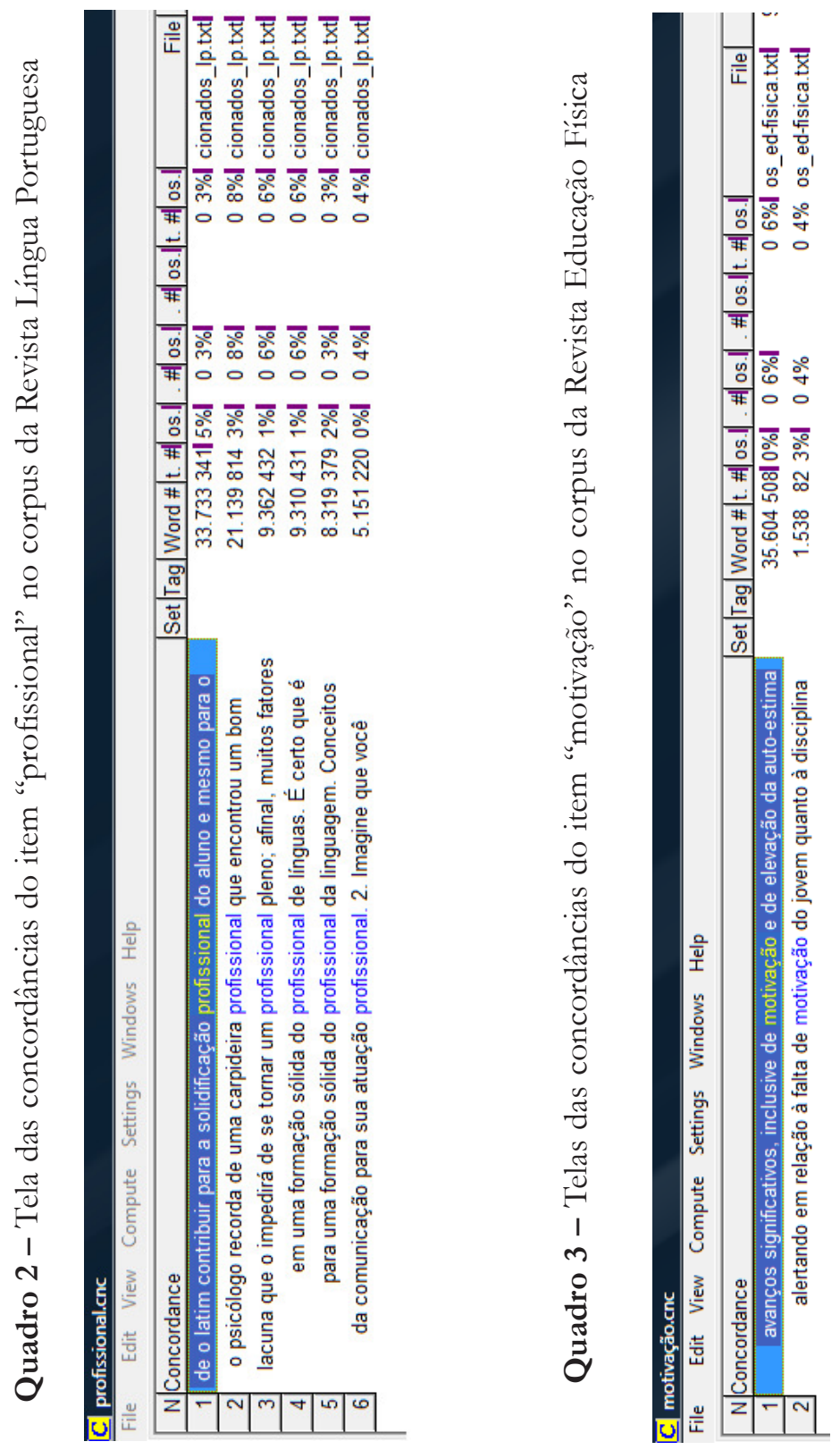


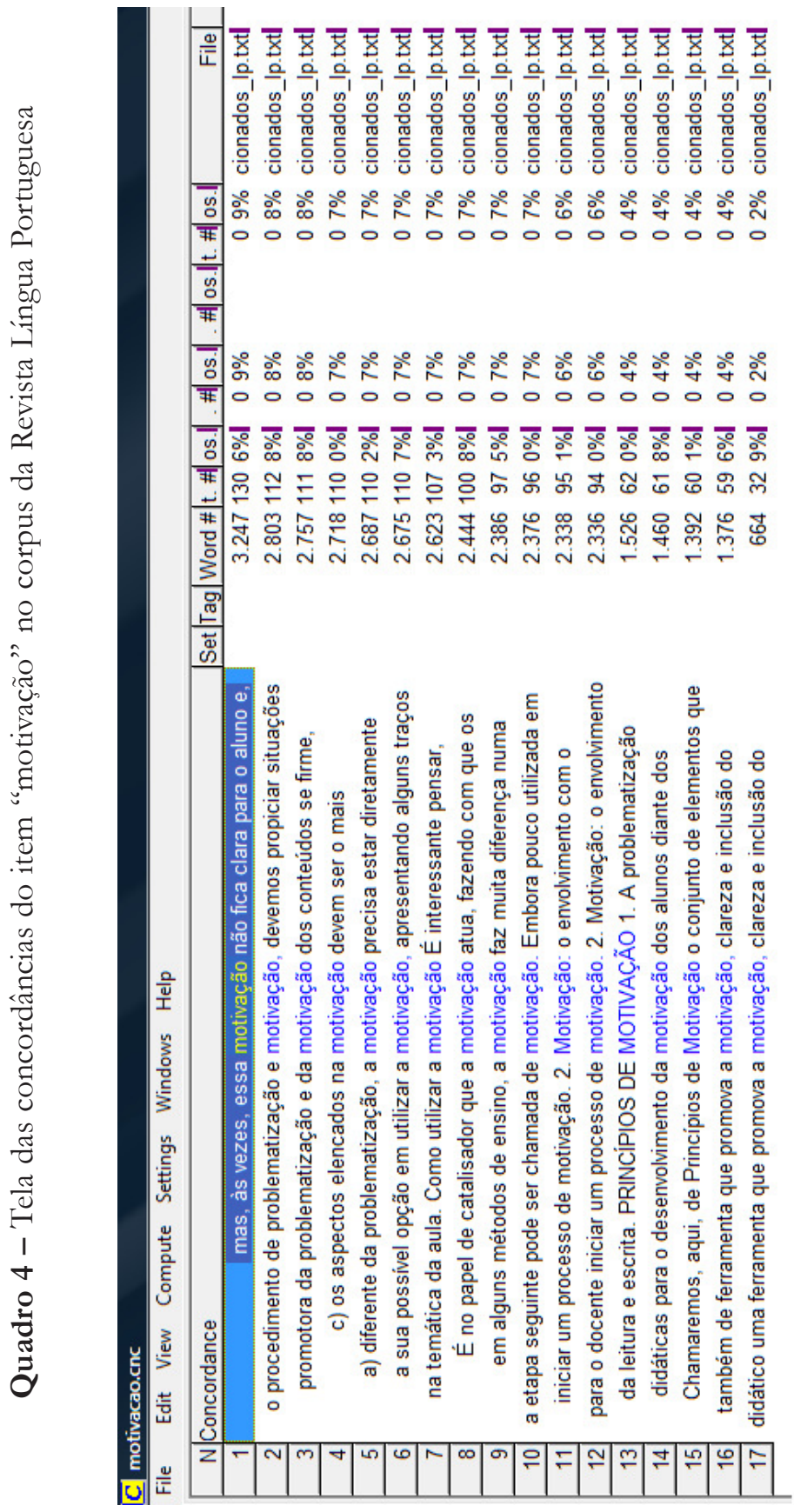




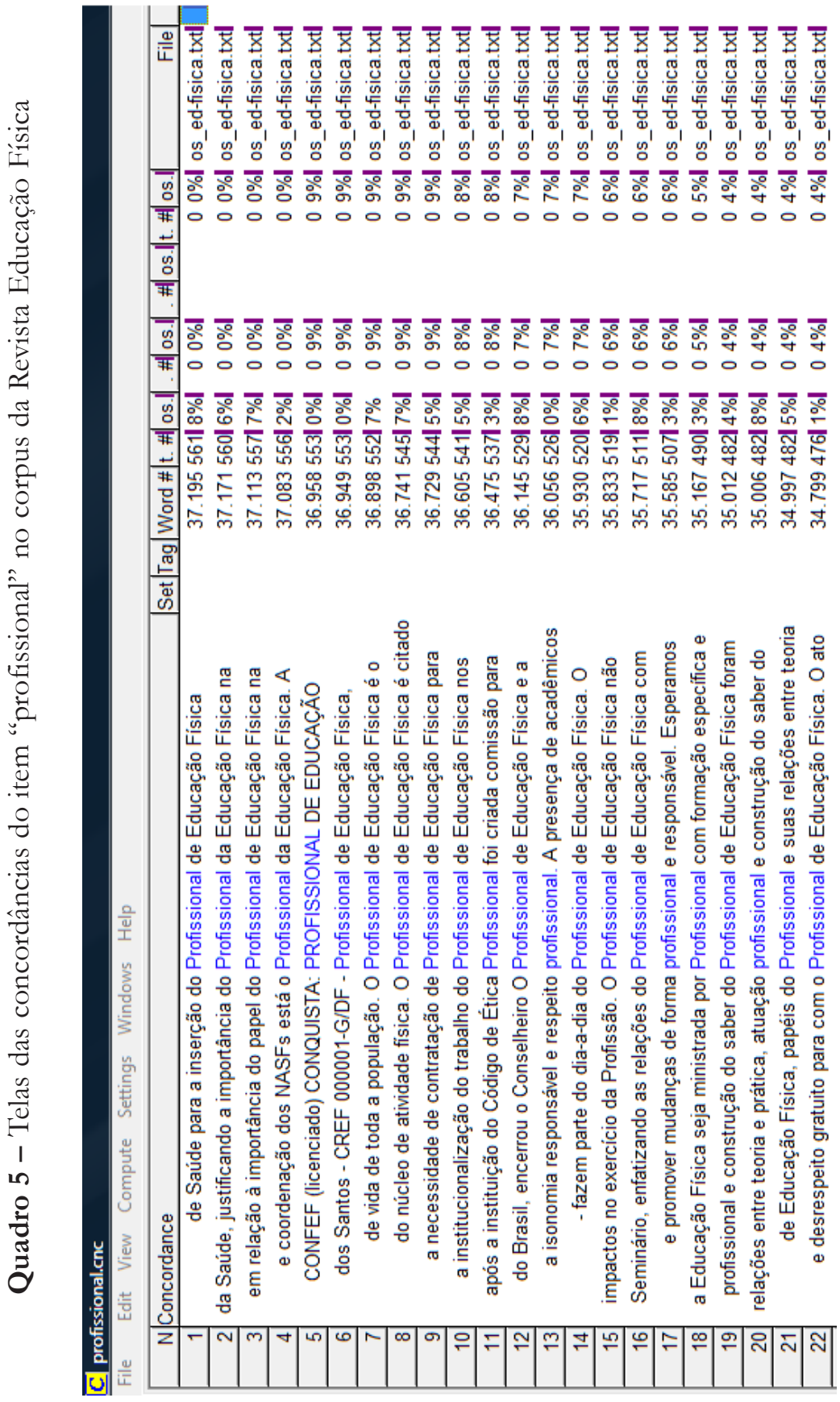

Signum: Estud. Ling., Londrina, n. 14/1, p. 523-550, jun. 2011 
$\bar{z} \bar{z} \bar{z} \bar{z} \bar{z} \bar{z} \bar{z} \bar{z} \bar{z} \bar{z} \bar{z} \bar{z} \bar{z} \bar{z} \bar{z} \bar{z} \bar{z} \bar{z} \bar{z} \bar{z} \bar{z} \bar{z} \bar{z} \bar{z} \bar{z}$

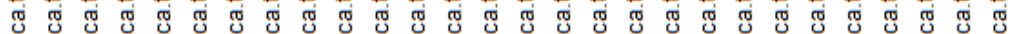

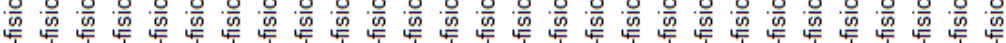

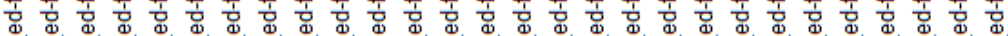

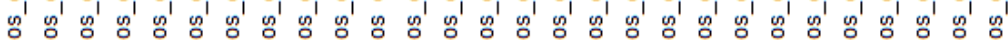

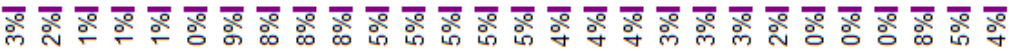
000000000000000000000000000000

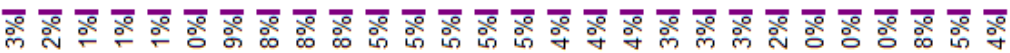

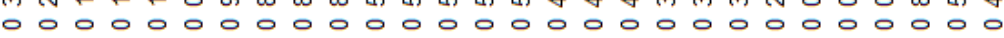

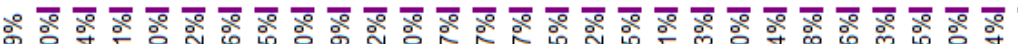

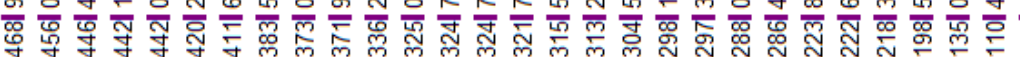

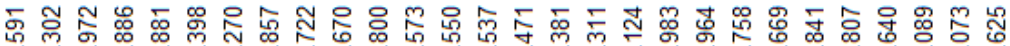

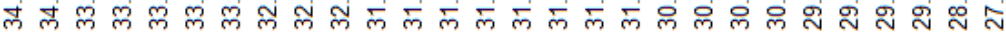

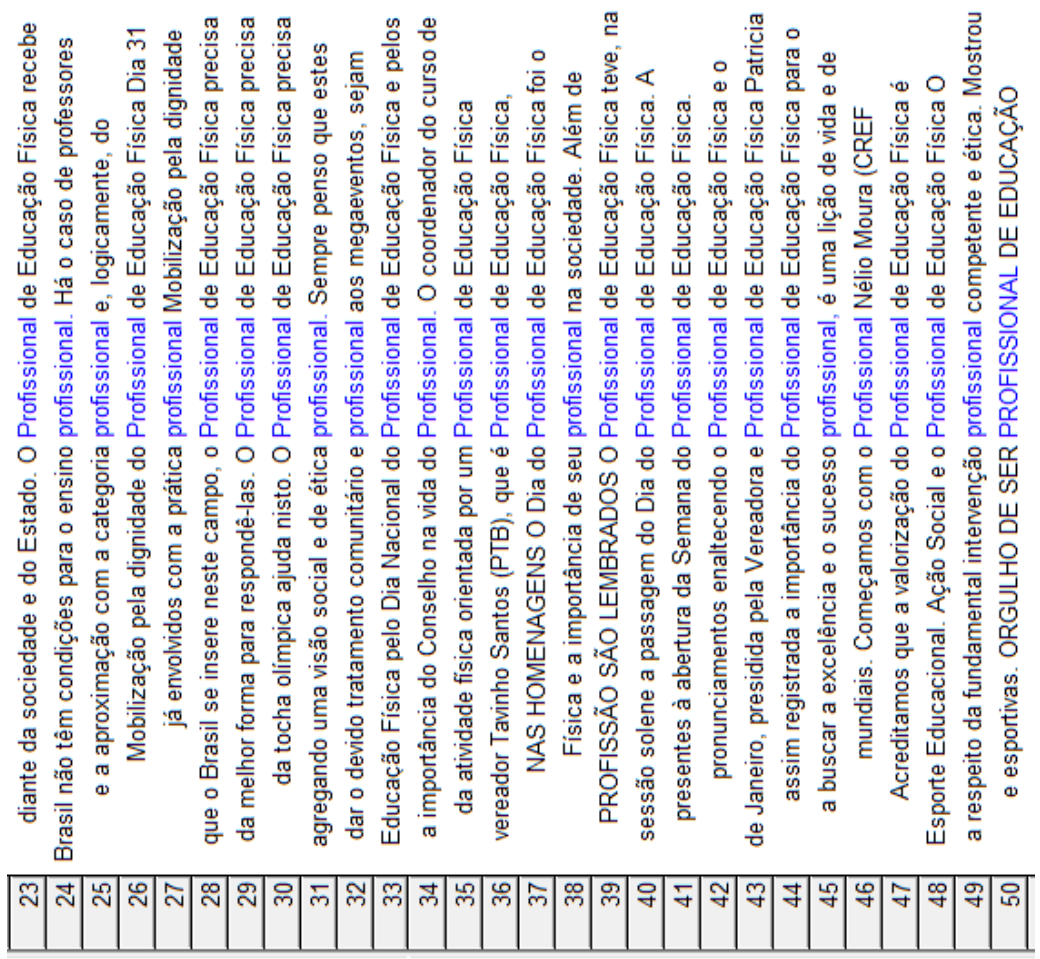


$\bar{x} \bar{x} \bar{x} \bar{x} \bar{x} \bar{x} \bar{x} \bar{x} \bar{x} \bar{x} \bar{x} \bar{x} \bar{x} \bar{x} \bar{x} \bar{x} \bar{x} \bar{x} \bar{x}$ ల్ల

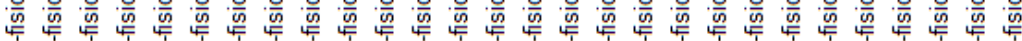

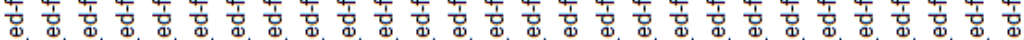

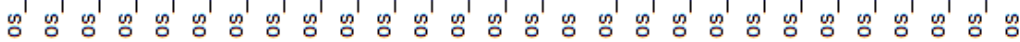

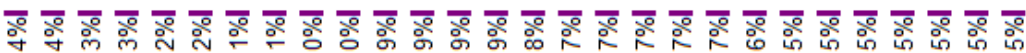
0000000000000000000000000000

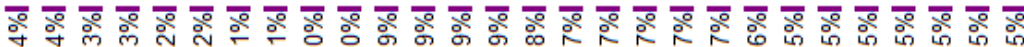
0000000000000000000000000000

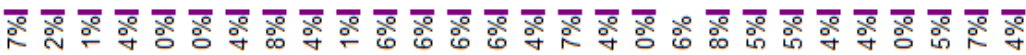

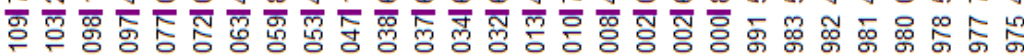

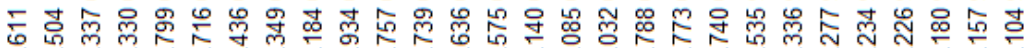
ล ล

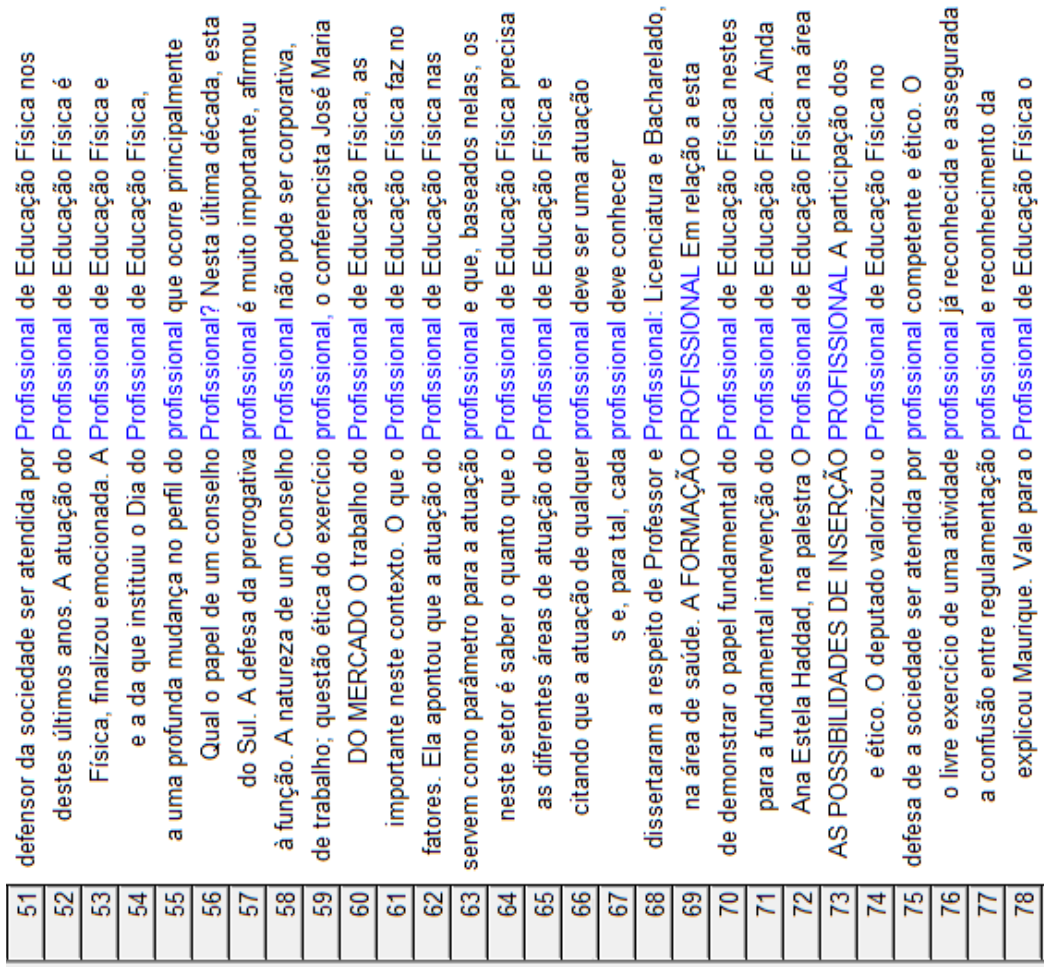

Signum: Estud. Ling., Londrina, n. 14/1, p. 523-550, jun. 2011 
$\bar{z} \bar{z} \bar{z} \bar{z} \bar{z} \bar{z} \bar{z} \bar{z} \bar{z} \bar{z} \bar{z} \bar{z} \bar{z} \bar{z} \bar{z} \bar{z} \bar{z} \bar{z} \bar{z} \bar{z} \bar{z}$

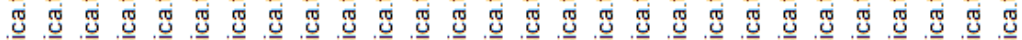

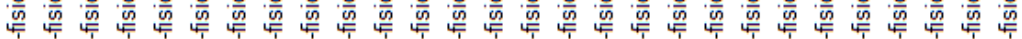

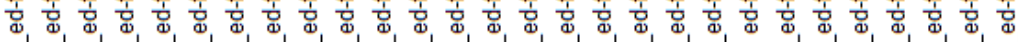

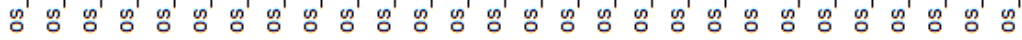

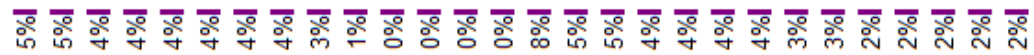

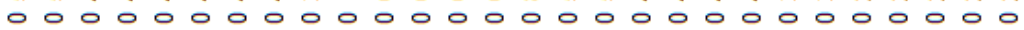

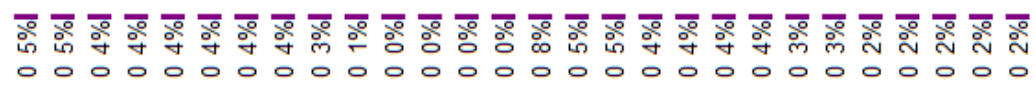

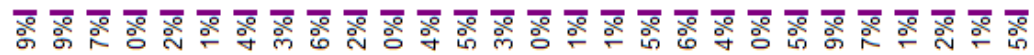

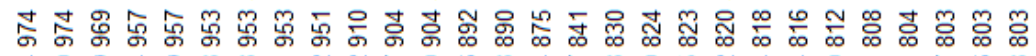

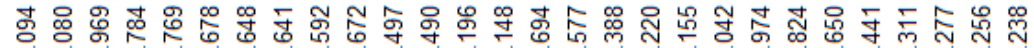

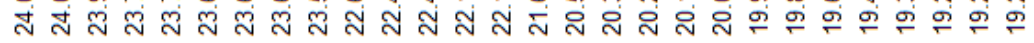

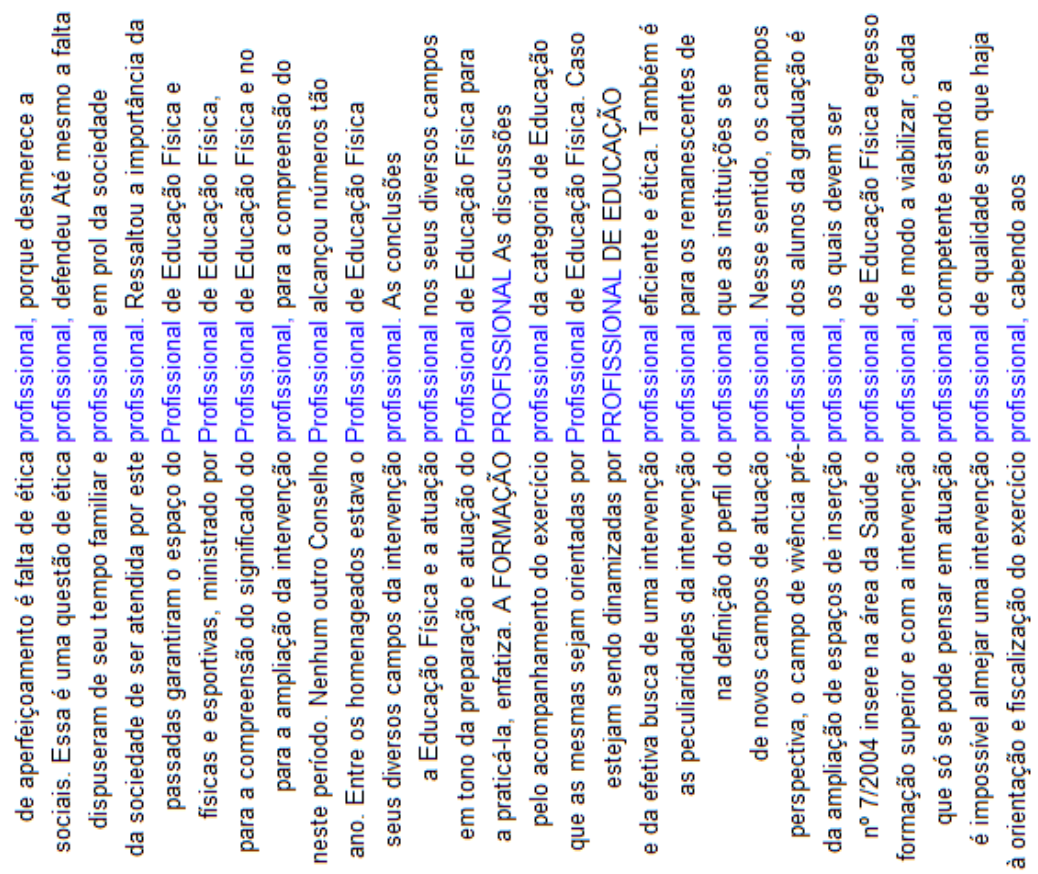

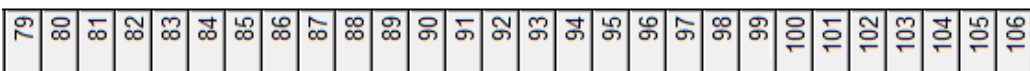


$\bar{z} \bar{z} \bar{z} \bar{z} \bar{z} \bar{z} \bar{z} \bar{z} \bar{z} \bar{z} \bar{z} \bar{z} \bar{z} \bar{z} \bar{z} \bar{z} \bar{z} \bar{z} \bar{z} \bar{z} \bar{z}$

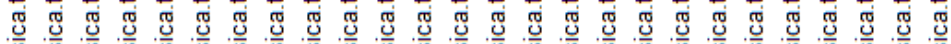

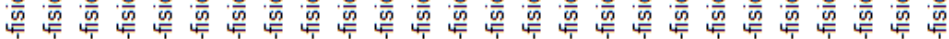

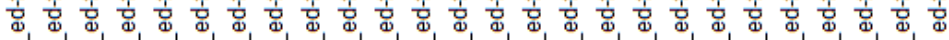

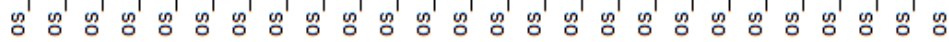

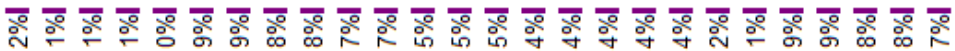
00000000000000000000000000

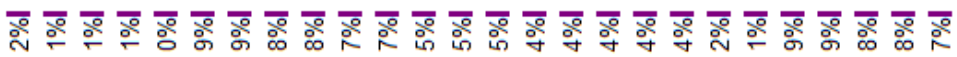
00000000000000000000000000

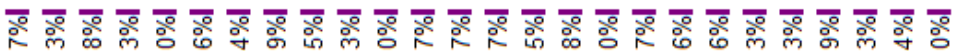

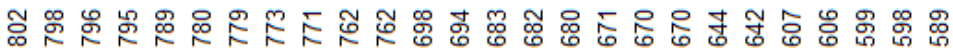

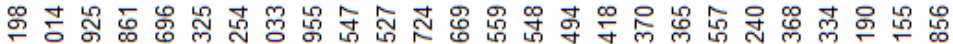

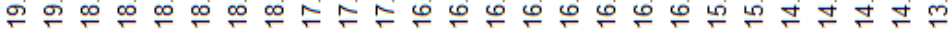

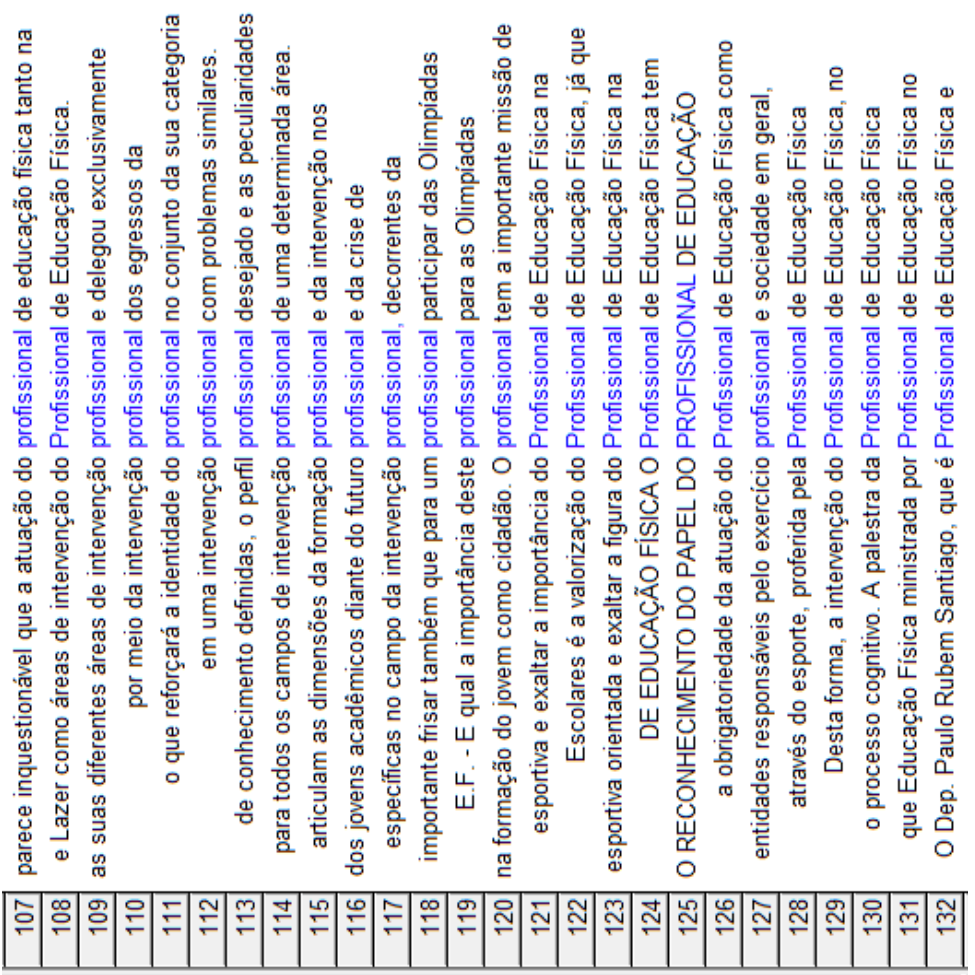




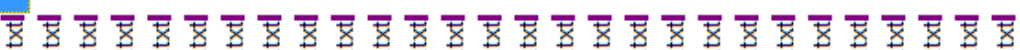
లై

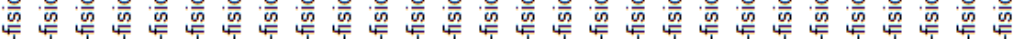

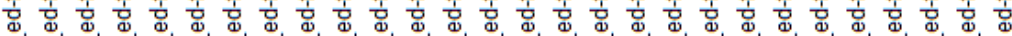

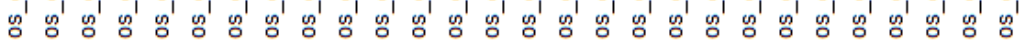

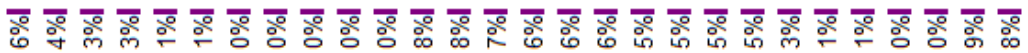
0000000000000000000000000000

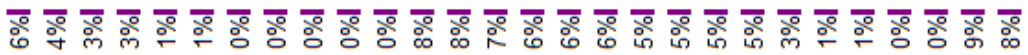

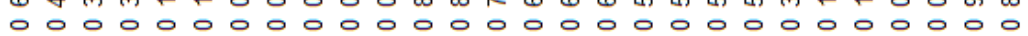

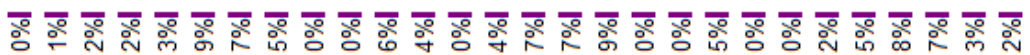

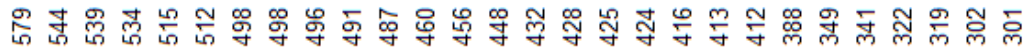

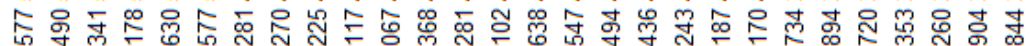

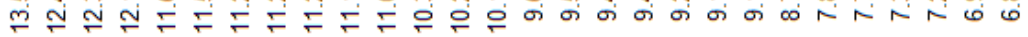

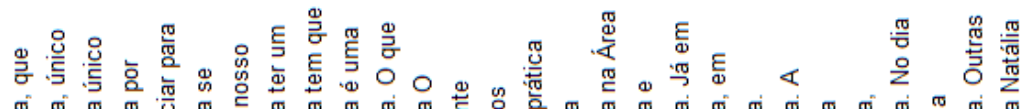
శ5

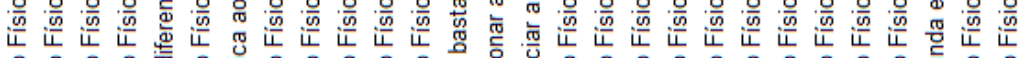

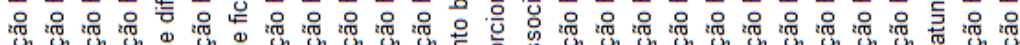

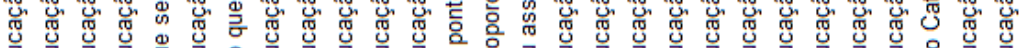

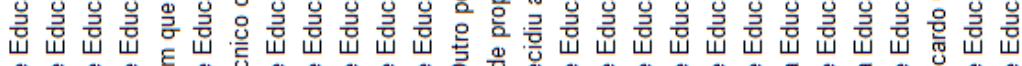

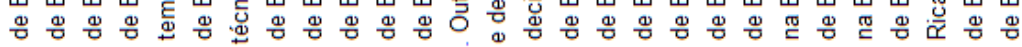

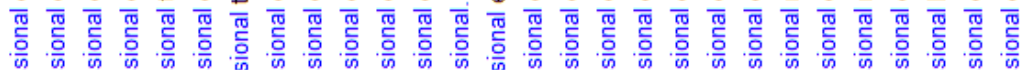

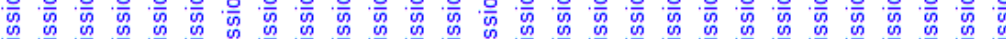

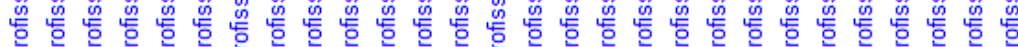

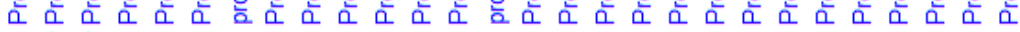

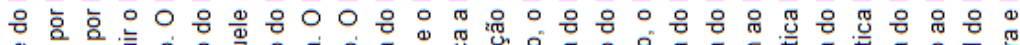

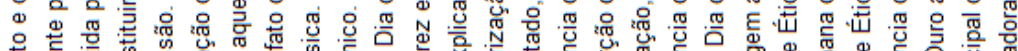

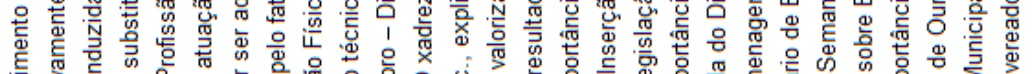

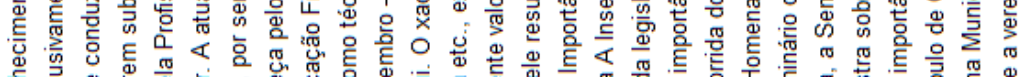

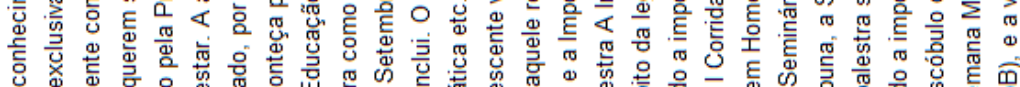

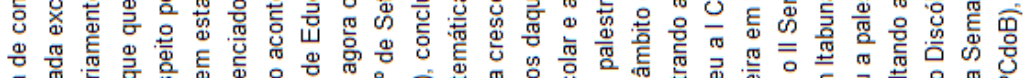

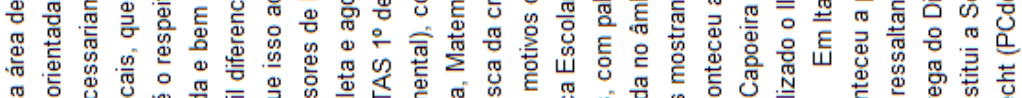

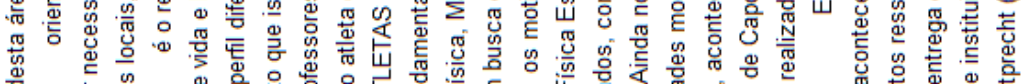

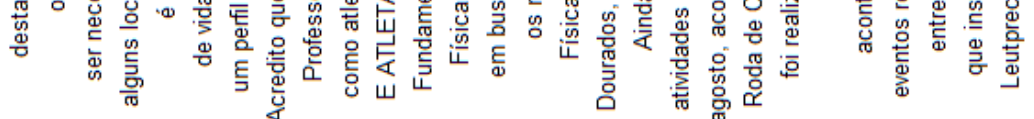

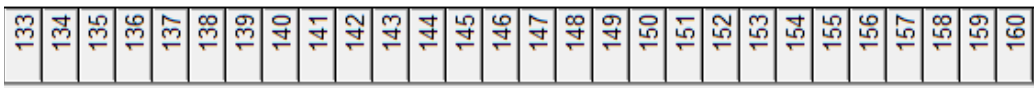


$\bar{x} \bar{x} \bar{x} \bar{x} \bar{x} \bar{x} \bar{x} \bar{x} \bar{x} \bar{x} \bar{x} \bar{x} \bar{x} \bar{x} \bar{x} \bar{x} \bar{x}$ 西

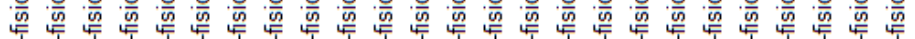

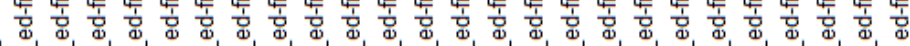

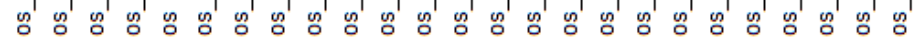

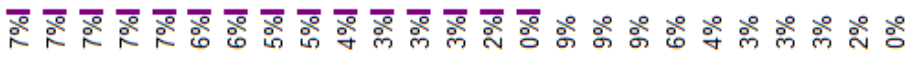
0000000000000000000000000

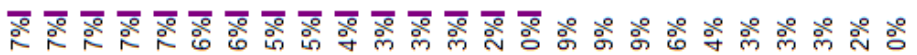
0000000000000000000000000

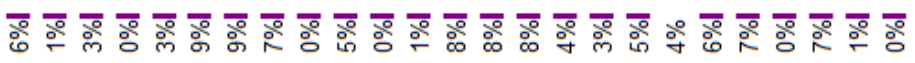

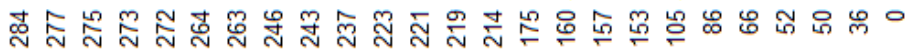

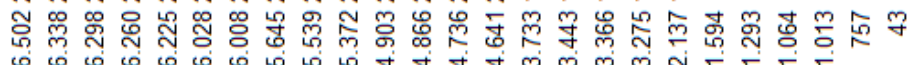

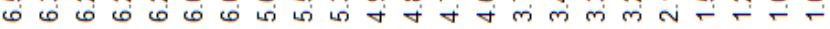

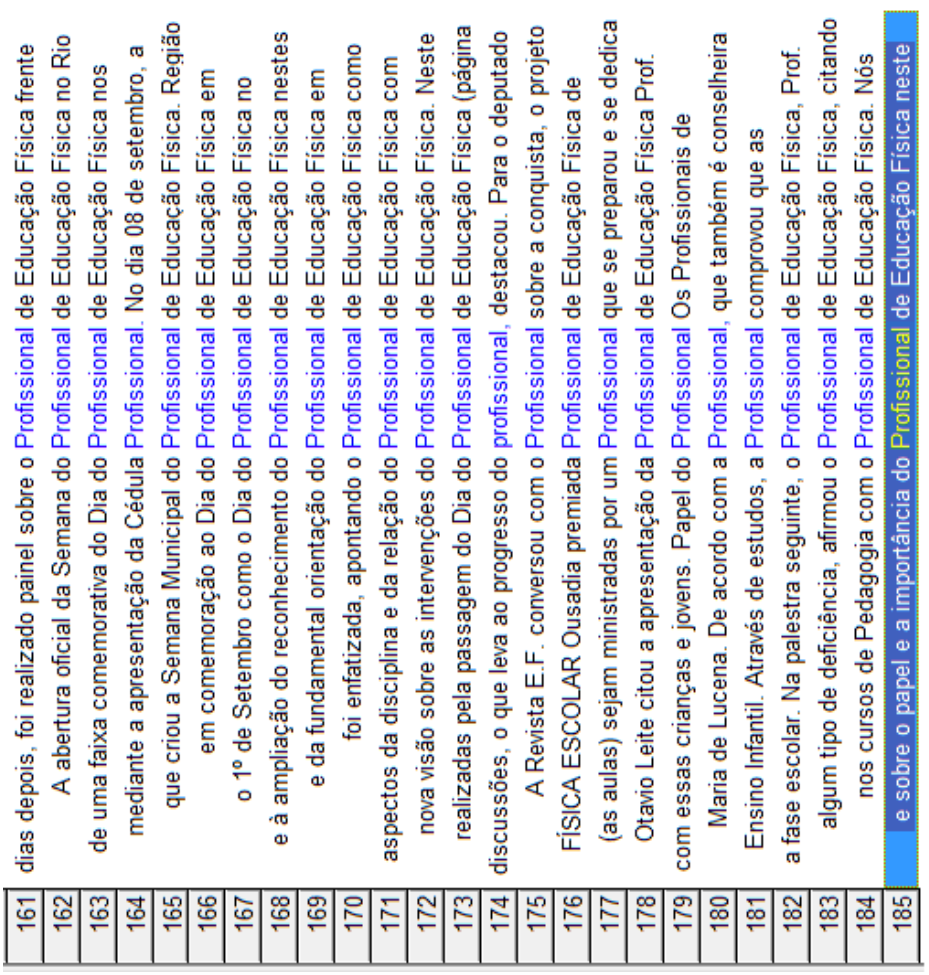


Salientamos que nossa análise, embora incipiente, já demonstra resultados significativos no que tange à comparação linguística do corpus destas duas profissões, distintas em termos legais, embora integrantes da esfera educacional. O recurso Wordlist permite perceber que a visão de "profissional" difere muito na comparação entre os corpora: a revista Educação Física possui 373 ocorrências das palavras profissional e profissionais, ao passo que a Língua Portuguesa apresenta, somados, apenas 10 .

Também com relação à atribuição, a palavra "motivação" nos chama a atenção: parece que o profissional de Letras recorre muito mais a este recurso do que o de Educação Física. Particularmente perturbador a esse respeito é que, entre os licenciados em Letras, esse conceito representa um ônus extra e pesado para o profissional: não é o cliente que precisa estar motivado para cooperar; e sim o profissional (professor) é que seria o responsável pela ausência de empenho do cliente (aluno).

As telas do Concord apresentam as listas de ocorrência de nossos nódulos de estudo, juntamente com o cotexto que o acompanha (texto ao redor). A visualização atenta destes recortes revela indícios contrastivos entre as duas profissões. Tal revelação reforça o que pretendemos demonstrar mais adiante, com a evolução de nossas pesquisas: a oposição endogenia versus exogenia discursiva demonstrada no corpus de estudo.

Richter (2008) adverte que profissões não regulamentadas por lei federal, ou seja, desprovidas de personalidade jurídica e de autonomia para se autodeterminarem por meio dos Conselhos - caso do Profissional de Letras - situam-se em entrelugares sociodiscursivos cujos mecanismos de enunciação não conseguem acionar efeitos de verdade (efeitos de sentido que "dão fé" ao leigo e à sociedade) nem efeitos de prestígio (autoconstituição de uma imagem profissional que muito se aproxima do fenômeno do ethos, mas com ênfase no valor social agregado a essa imagem - valor do profissional, de seu trabalho, de seu conhecimento, de sua formação). É nossa firme opinião que somente a regulamentação do Profissional de Letras pode alavancar a reversão desses mecanismos perversos de despersonalização laboral. 


\section{Conclusão}

Ao interagirmos com as principais ideias dos autores acima mencionados, procuramos defender a estabilização das expectativas por meio da regulamentação da profissão de Letras, a exemplo da já emancipada Educação Física. Agregando valor à posição do professor e status a seu papel social, acreditamos que tal processo terá resultados percebidos em âmbitos ainda maiores do que a esfera sistêmica educacional.

Em síntese, podemos assegurar que os motivos apresentados são suficientes para movimentar a batalha pela regulamentação nas Letras, dada a relevância social do papel deste profissional. Nesse sentido, a Teoria Holística da Atividade reforça que não bastam boas intenções, é preciso afastar-se das preocupações meramente discursivas e apropriar-se de uma postura real de mudança na ação.

As distorções acerca do papel social do professor contribuem para a desfiguração da sua imagem, restando buscar a maioridade para reverter a situação recorrente de ingerência de outros sistemas. Permanecendo na passividade, o docente de línguas acaba por carregar consigo o peso das tarefas de uma profissão organizada alopoieticamente, cujo papel social permanece obscuro em meio às práticas sociais. Desta forma, não basta reconhecer a importância do profissional de Letras - é preciso regulamentar a sua atividade, conferindo personalidade jurídica, voz ativa e poder de ação na organização do trabalho deste formador de profissões.

\section{Anexo 1}

Tradução de Carlos Alberto Nunes. Disponível em: <http:// omundoeumpalco.zip.net/arch2009-10-18_2009-10-24.html>.

O mundo todo é um palco, os homens e as mulheres,

meros artistas, que entram nele e saem.

Muitos papéis cada um tem no seu tempo;

sete atos, sete idades. Na primeira, no braço da ama grita e baba o infante. 
O escolar lamuriento, após, com a mala,

de rosto matinal, como serpente

se arrasta para a escola, a contragosto.

$O$ amante vem depois, fornalha acesa,

celebrando em balada dolorida

as sobrancelhas da mulher amada.

A seguir, estadeia-se o soldado,

cheio de juras feitas sem propósito,

com barba de leopardo, mui zeloso

nos pontos de honra, a questionar sem causa,

que a falaz glória busca

até mesmo na boca dos canhões.

Segue-se o juir, com o ventre bem forrado

de cevados capões, olhar severo,

barba cuidada, impando de sentenças

e de casos da prática; desta arte

seu papel representa. A sexta idade

em magras pantalonas tremelica,

óculos no nariz, bolsa de lado,

calças da mocidade bem poupadas,

mundo amplo em demasia para pernas

tão mirradas, a voz viril e forte,

que ao falsete infantil voltou de novo,

chia e sopra ao cantar. A última cena,

remate desta história aventurosa,

é mero olvido, uma segunda infância,

falha de vista, dentes, gosto e tudo.

\section{Referências}

BRONCKART. J.P. Por que e como analisar o trabalho do professor. In: Atividade de linguagem, discurso e desenvolvimento humano. Trad.

A.R. Machado; M.L.M. Matêncio. Campinas: Mercado de Letras, 2006. p. 203-231. 
DAHRENDORF, R. Homo Sociologicus. Londres: Routledge and Kegan Paul, 1969.

ELIAS, N. Os estabelecidos e os outsiders: sociologia das relações de poder a partir de uma pequena comunidade. Rio de Janeiro: Jorge Zahar, 2000 .

LUHMANN, N. Sociologia do Direito I. Rio de Janeiro: Tempo Brasileiro, 1983.

MACHADO, A.R. Por uma concepção ampliada do trabalho do professor. In: GUIMARÃES, A.M.M; MACHADO, A.R.; COUTINHO, A. (Orgs.). O interacionismo sociodiscursivo: questões epistemológicas e metodológicas. Campinas: Mercado de Letras, 2007. p. 77-97.

RICHTER, M.G. Conceitos de aquisição da linguagem na perspectiva da Linguística de Corpus: um estudo empregando um novo mapeador semântico. [s.d.] (texto inédito)

- Aquisição, representação e atividade. Santa Maria: UFSM, PPGLEditores, 2008.

Saberes didáticos: em favor do ensino ou da aprendizagem? In: CÍRCULO DE ESTUDOS LINGUÍSTICOS DO SUL, 9., PalhoçaSC, 2010. Anais... Palhoça: Universidade do Sul de Santa Catarina, 2010. p. 1-11.

.; GARCIA, J.R.C. A profissionalização do professor: condição necessária para uma prática respeitável. Linguagens \& Cidadania. Santa Maria, ano $8 \mathrm{n}^{\circ}$ 1, jan-jun.2006. Disponível em <http:// jararaca.ufsm.br/websites/1\&c/download/Artigos/L\&C_1S_06/ Jaci_MarcosL\&C06.pdf>. Acesso em: 30 set.2009.

.; PAZ, D.M.S.; CAVICHIOLI, F.; PINTO, C.M. O modelo holístico como alternativa à formação docente. In: CONGRESSO LATINO-AMERICANO SOBRE FORMAÇÃO DE PROFESSORES DE LÍNGUAS, 1., Florianópolis, 2006. Anais... 
Florianópolis: Universidade Federal de Santa Catarina, 2006. Disponível em: <http://www.cce.ufsc.br/ clafpl/81_Marcos_Richter_\%20 Dioni_Paz_Fabricia_Cavichioli_e_Candida.pdf $>$. Acesso em: 30 set. 2009.

STEINHILBER, J. (Org.). Profissional de Educação Física... existe? Rio de Janeiro: Sprint, 1996.

VARGAS, A. Regulamentando uma realidade. In: STEINHELBER, J. (Org.). Profissional de Educação Física... existe? Rio de Janeiro: Sprint, 1996. p. 89-95. 